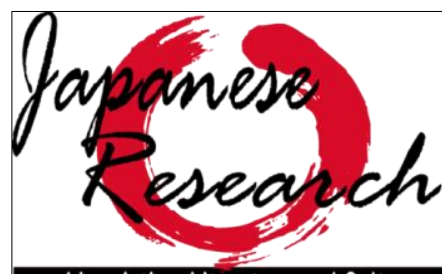

on Linguistics, Literature and Culture
Japanese Research on Linguistics, Literature, and Culture

Vol. 1 No. 2 May 2019, Hal. 112-128

ISSN online: $2655-4836$

http://publikasi.dinus.ac.id/index.php/irllc/article/view/2461/1539

DOI : 10.33633/ir.v1i2.2461

Published by Universitas Dian Nuswantoro, Semarang

\title{
Pandangan Masyarakat Jepang terhadap Tokoh Transeksual dalam Film Karera Ga Honki De Amu Toki Wa
}

\author{
Budi Mulyadi, Aida Kurniasih \\ Universitas Diponegoro \\ budi.mulyadi09@gmail.com
}

Article History: Submitted date 2019-05-16 ; Accepted date 2019-05-25; Published date 2019-06-01

\begin{abstract}
This paper entitled the view of Japanese society towards transsexual character in the movie "Karera ga honki de amu toki wa". The main goal of this writing paper is to know about the view of Japanese society towards transsexual character which described in the movie Karera ga honki de amu toki wa. To analyze the description of heteronormativity in society that Naoko Ogigami wishes to convey in this film, we use the labeling theory in Narwoko and Suyanto and the literary sociology theory of Wellek and Warren by focusing on the second point, namely the sociology of literature. From the results of the analysis, it can be explained that the views of Japanese society on the transsexual figures portrayed in this film are not good. The act of labeling Rekso as a bad character in the film illustrates that there are still some Japanese people who have not accepted the existence of transsexuals. From the five aspects of sociology analyzed for this film, it can be concluded that although Japan is a country that is considered tolerant, they have not been able to fully accept transgender people in their social environment. Especially in aspects such as education, social and cultural aspects.
\end{abstract}

Keywords: Film, Japanese Society, View, Transsexual, Character

\begin{abstract}
Abstrak
Judul penelitian ini adalah pandangan masyarakat Jepang terhadap tokoh transeksual yang digambarkan dalam film "Karera ga honki de amu toki wa". Tujuan penelitian ini untuk mengetahui pandangan masyarakat Jepang terhadap tokoh transeksual yang digambarkan dalam film ini. Untuk menganalisis gambaran tentang heteronormativitas di masyarakat yang hendak disampaikan oleh Naoko Ogigami pada film ini maka penulis menggunakan teori labeling dalam Narwoko dan Suyanto dan teori sosiologi sastra dari Wellek dan Warren dengan memfokuskan pada butir kedua, yaitu sosiologi karya sastra. Dari hasil analisis dapat dijelaskan bahwa pandangan masyarakat Jepang terhadap tokoh transeksual yang digambarkan dalam film "Karera ga honki de amu toki wa" adalah tidak baik. Tindakan pemberian cap tidak baik kepada tokoh transeksual Rinko dalam film ini
\end{abstract}


menggambarkan bahwa masih ada sebagian masyarakat Jepang yang belum menerima eksistensi kaum transeksual. Dari lima aspek sosiologi yang dianalisis mengenai film ini dapat disimpulkan bahwa meskipun Jepang adalah negara yang dianggap toleran, mereka belum mampu sepenuhnya menerima kaum transgender dalam lingkungan sosial mereka. Khususnya pada aspek-aspek seperti aspek pendidikan, sosial dan Budaya,

Kata Kunci : Film, Masyarakat Jepang, Pandangan, Trasnseksual, Karakter

\section{Pendahuluan}

Film merupakan salah satu hasil karya seni yang unik dan menarik. Film merupakan produk karya seni dan budaya yang memiliki nilai guna karena bertujuan memberikan hiburan dan kepuasan bagi penonton. Dalam kaitannya dengan karya sastra, film juga merupakan hasil dari karya yang mempunyai garis persamaan dengan karya sastra karena sama-sama memiliki sifat naratif. Dengan demikian film dapat dikatakan juga sebagai salah satu produk karya sastra karena keduanya mempunyai kesamaan, yaitu dalam hal penyampaian pesan melalui sebuah narasi. Pratista dalam buku Memahami Film, mengartikan film sebagai produk karya seni dan budaya yang bertujuan untuk memberikan hiburan dan kepuasan batin bagi para penikmatnya (2008:40).

Selain memberikan hiburan dan kepuasan batin, film juga sering kali mengandung pesan-pesan sosial yang hendak disampaikan oleh penciptanya. Banyak penggiat film yang juga peka terhadap keadaan sosial yang ada di masyarakat. Kondisi sosial masyarakat ini dijadikan sebagai ide cerita yang kemudian disampaikan kembali kepada masyarakat dalam bentuk film

Salah satu sutradara yang juga pernah membuat film berdasarkan ide yang diperoleh dari realita sosial yang ada adalah Naoko Ogigami. Naoko Ogigami adalah salah satu sutradara sekaligus penulis naskah film dari Jepang yang cukup sukses. Beberapa karyanya sudah memenangkan berbagai penghargaan. Karyanya yang paling banyak mendapat penghargaan berjudul Hoshino-kun, Yumino-kun atau 星 $\zeta く$ ・夢 $\zeta ん$ (2001) yang berhasil memenangkan 3 kategori dalam PIA Film Festival. Tidak hanya itu, karyanya yang terbaru berjudul Karera Ga Honki De Amu Toki Wa 彼らが本気で編むときは(2017) atau dikenal juga 
dengan judul Close-Knit juga berhasil memenangkan penghargaan kategori Audience Award, pada aja penghargaan film Tromsø International Film Festival.

Dalam sebuah wawancara tentang film Karera Ga Honki De Amu Toki Wa di Festival Film Berlin, Naoko Ogigami mengungkapkan, "Saat berusia 20 tahun saya pernah tinggal di Los Angeles. Saya mempunyai teman seorang gay, lesbian, dan trasgender. Ketika saya kembali ke Jepang, saya tidak dapat menemukannya. Saya selalu merasa hal itu aneh. Dua tahun yang lalu, saya membaca koran tentang transgender, dia berusia 14 tahun ketika mengatakan kepada ibunya bahwa dia ingin mempunyai payudara, dia ingin menjadi seorang perempuan. Kemudian ibunya membuatkan payudara palsu. Kejadian itu memberiku banyak inspirasi. Saya menemui ibunya dan mempunyai ketertarikan dengan mereka. Saya mendapat cerita tentangnya dan kemudian mengembangkannya."

Dari kutipan wawancara tersebut dapat disimpulkan bahwa penulis naskah film Karera Ga Honki De Amu Toki Wa ini mengangkat cerita tentang fakta mengenai keadaan sosial yang ada di masyarakat Jepang. Kebanyakan unsur-unsur dalam karya sastra bersifat sosial, yaitu norma-norma yang dapat tumbuh dalam masyarakat. Karya sastra juga mewakili kehidupan, sedang kehidupan adalah kenyataan sosial yang dalam diri sastrawan dapat menjadi objek penciptaan karya sastra (Noor, 2015:48).

Sosiologi merupakan disiplin ilmu tentang kehidupan masyarakat yang objek kajiannya mencakup fakta sosial, definisi sosial dan perilaku sosial yang menunjukan hubungan interaksi sosial dalam suatu masyarakat. Sedangkan masyarakat sendiri adalah sekumpulan manusia yang saling berinteraksi, memiliki adat istiadat, norma-norma, hukum, serta aturan yang mengatur semua pola tingkah laku; terjadi kontinuitas dalam waktu; dan diikat dengan rasa identitas yang kuat mengikat warganya (Koentjaraningrat dalam Kurniawan 2012: 4-5). Sosiologi adalah ilmu yang mempelajari struktur sosial dan proses-proses sosial termasuk perubahan sosial. Singkat kata, sosiologi tidak hanya merupakan kumpulan subdisiplin segala bidang kehidupan, melainkan merupakan sebuah studi tentang masyarakat (Soemardjan dan Soemardi dalam Narwoko dan Bagong Suyanto (Ed.) , 2013:4). Dengan demikian sosiologi sastra di sini objek kajiannya adalah sastra, sedangkan sosiologi berguna sebagai ilmu untuk 
memahami gejala sosial yang ada dalam sastra baik penulis, fakta sastra maupun pembaca dalam relasi dialektiknya dengan kondisi masyarakat yang menghidupi penulis, masyarakat yang digambarkan, dan pembaca sebagai individu kolektif yang menghidupi masyarakat (Kurniawan, 2012:5)

Film Karera Ga Honki De Amu Toki Wa (Close-Knit) merupakan film karya Naoko Ogigami yang dirilis pada tahun 2017. Film ini menceritakan seorang gadis 11 tahun bernama Tomo yang tiba-tiba terpaksa harus tinggal bersama pamannya yaitu Makio karena ditinggalkan oleh ibunya, Hiromi. Sementara itu Makio telah tinggal dengan kekasihnya yang bernama Rinko. Rinko adalah seorang transeksual yang bekerja di panti jompo tempat di mana ibu Makio tinggal. Sementara itu Rinko sangat menyukai Tomo, dia merawat Tomo seperti merawat anak kandungnya sendiri. Tomo yang bingung kemudian mencoba memahami identitas seksual Rinko dengan membaca buku terkait masalah transeksual.

Seiring berjalannya waktu, Tomo bisa merasakan kasih sayang ibu yang tidak dia dapatkan dari ibu kandungnya, Tomo pun mulai menerima Rinko. Konflik terjadi saat ibu dari Kai yaitu Naomi, bertemu dengan Tomo di pusat perbelanjaan. Dia melihat Tomo bersama Rinko kemudian melarang Tomo untuk berhubungan dengan Rinko. Naomi memberikan cap 'orang aneh' pada Rinko sehingga membuat Tomo marah dan menyemprotkan sabun cuci padanya. Hal ini menyebabkan Tomo dan Rinko harus berurusan dengan polisi. Naomi diamdiam melaporkan Rinko pada lembaga perlindungan anak. Saat pemeriksaan yang dilakukan lembaga perlindungan anak yang mereka melihat kedekatan Rinko dan Tomo dan tidak menemukan masalah apapun sehingga lembaga perlindungan anak membebaskan mereka. Rinko dan Makio berencana untuk mengadopsi Tomo karena Rinko akan segera merubah catatan warga sipilnya sebagai seorang perempuan, akan tetapi tidak lama kemudian Hiromi kembali untuk menjemput Tomo. Terjadi perdebatan di antara mereka. Hiromi tidak menginginkan Tomo diadopsi oleh seorang transeksual. Pada akhirnya Tomo memutuskan untuk kembali tinggal bersama ibunya, meninggalkan Makio dan Rinko. 
Dalam film ini Naoko Ogigami menggambarkan sebagian masyarakat Jepang yang masih sulit menerima perilaku yang dianggap menyimpang seperti LGBT dalam lingkungan yang dekat dengan mereka, misalnya dalam pertemanan atau keluarga

Berkaitan dengan film Karera Ga Honki De Amu Toki Wa (Close-Knit) yang juga menceritakan tokoh transeksual, Naoko Ogigami menggambarkan masyarakat Jepang sebagai masyarakat yang belum bisa sepenuhnya menerima keberadaan seorang transeksual terlebih lagi jika mereka berada dekat dengan keluarga atau kerabat mereka. Juli L. Nagoshi (2008) dalam bukunya yang berjudul Gender And Sexual Identity, menyampaikan bahwa,

"Orang-orang transgender dan transeksual sering disebut hanya dengan sebutan "trans". "Trans" berasal dari kata Latin trans, yang secara umum berarti "melintasi, melampaui, atau melalui". Orang-orang transgender dan transeksual menantang salah satu kategori identitas paling mendasar bagi manusia, yaitu gender, dan dalam banyak hal menantang ide-ide mendasar tentang sifat dari setiap identitas yang penting secara sosial, bagaimana kita berteori dan melakukan penelitian tentang identitas, dan bagaimana kita mengembangkan dan mengimplementasikan intervensi praktis terkait dengan identitas sosial."

Transgenderisme dapat didefinisikan sebagai pemutusan peran gender dan identitas gender dan/atau melintasi batas-batas gender ke gender lain (Green 2004). Orang transgender biasanya mengekspresikan identitas gender di luar definisi heteronormatif, tetapi memiliki sedikit niat atau tidak ada niat melakukan operasi penggantian kelamin atau perawatan hormon (Bornstein 1994). Orang transeksual dapat berupa pra-transisi/ operasi, dalam transisi/ dalam proses penggantian kelamin melalui terapi hormon dan bedah, atau pasca-transisi/ operasi (Hird, 2002). Pra operasi berarti bahwa operasi genital belum dilakukan, tetapi orang itu berniat atau ingin melakukannya dan dengan asumsi hidup penuh atau paruh waktu sebagai jenis kelamin lain, sementara pasca operasi didefinisikan oleh orang yang telah menjalani operasi rekonstruksi genital dan sepenuhnya hidup dalam jenis kelamin lain (Bornstein, 1994). Transgender hidup dengan identitas gender yang berbeda dari biner gender tradisional dan identitas gender mereka telah melanggar konsep heteronormatif laki-laki - perempuan sekaligus mencampurkan identitas dan aspek peran laki-laki - perempuan (Nagoshi: 2012).

Dalam penelitian ini penulis ingin mengetahui pandangan masyarakat Jepang terhadap tokoh transeksual dalam film karera ga honki de amu tokini dengan tujuan untuk mengetahui 
sudut pandang dan perlakukan masyarakat Jepang terhadap kaum transeksual dilihat dari aspek

sosiaol, pendidikan, budaya, agama dan ekonomi yang digambarkan dalam film ini sehingga melalui penelitian ini diharapkan bisa mengetahui bagaimana sikap masyarakat Jepang terhadap kaum marginal dalam hal ini kaum transeksual yang mulai berani menunjukkan eksistensi dirinya sebagai bagian dari kehidupan masyarakat.

Untuk menganalisis gambaran heteronormativitas di masyarakat yang hendak disampaikan oleh Naoko Ogigami pada film ini maka penulis menggunakan teori labeling dalam Narwoko dan Suyanto (2013) dan teori sosiologi sastra dari Wellek dan Warren (1989) dengan memfokuskan pada butir kedua yaitu sosiologi karya sastra.

\section{Hasil dan Pembahasan}

\subsection{Tindakan labeling atau pemberian cap}

Labeling merupakan suatu teori yang muncul akibat reaksi masyarakat terhadap perilaku seseorang yang dianggap menyimpang. Seseorang tersebut kemudian diberi cap atau label oleh lingkungan sekitarnya.

"Menurut para ahli, teori labeling mendefinisikan penyimpangan merupakan sesuatu yang bersifat relatif dan bahkan mungkin juga membingungkan. Karena untuk memahami apa yang dimaksud sebagai suatu tindakan menyimpang harus diuji melalui reaksi orang lain. Oleh karena itu, Becker salah seorang pencetus teori labeling, mendefinisikan penyimpangan sebagai "suatu konsekuensi dari penerapan aturan-aturan dan sanksi oleh orang lain kepada seorang pelanggar" (Narwoko dan Bagong Suyanto, 2011:115).

Karena menjadi individu transeksual oleh masyarakat Heteronormatif dianggap sebagai perilaku menyimpang, Rinko sebagai tokoh transeksual dan orang-orang terdekatnya kerap kali menerima tindakan labeling dari lingkungan mereka. tindakan labeling dalam film Karera ga Honki de Amu Toki wa (Close-Knit), di antaranya sebagai berikut.

1. Pemberian Cap Terhadap Keluarga Tomo

Tindakan pemberian cap terhadap keluarga Tomo ini dilakukan oleh teman-teman kelas Tomo. Mereka membuat tulisan ejekan di papan tulis sebagai berikut.

$$
\text { オガワトモ変態家族 }
$$


"Keluarganya aneh, Ogawa Tomo"

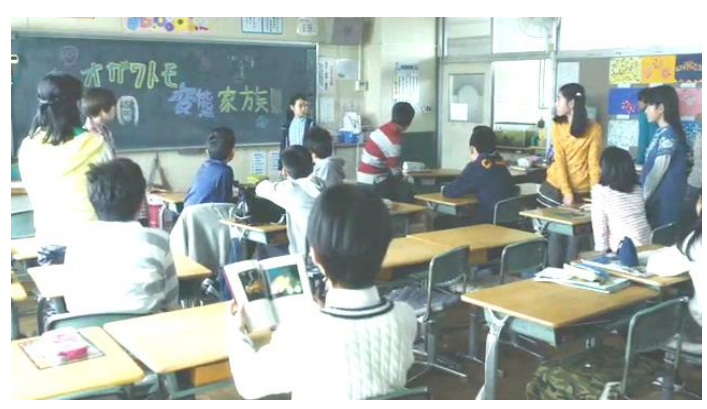

Gambar 1 (Close Knit 2017, Adegan 01:04:15)

Kejadian tersebut dialami Tomo ketika teman-temannya mengetahui bahwa Tomo memiliki anggota keluarga yang merupakan seorang transeksual. Kemudian mereka mengejek dan menertawakan Tomo.

\section{Pemberian Cap Terhadap Rinko}

Tindakan pemberian cap ini tidak hanya dilakukan oleh anak kecil atau teman-teman Tomo dan Kai saja. Naomi dan Hiromi juga memberikan cap atau label kepada Rinko karena merupakan seorang transeksual.

$$
\begin{aligned}
& \text { ナオミ：あなた大丈夫? } \\
& \text { ナオミ：ずいぶん変な人と一生にいるから } \\
& \text { ナオミ:いい、困ったらいつでもうちにいらっしやい } \\
& \text { ナオミ:カイもあたしもトモちゃん見办から } \\
& \text { ナオミ：あなたは一人じやないのよ } \\
& \text { ナオミ:余計なさわかもしれないけよ゙ } \\
& \text { ナオミ:あいうするの人とあまりいないほうが、ね }
\end{aligned}
$$

Naomi : Kamu baik-baik saja?

Naomi : Siapa orang aneh yang bersamamu itu?

Naomi : Dengar, kapanpun kamu butuh bantuan datang saja ke rumah

Naomi : aku dan Kai akan selalu bersama Tomo 


\begin{abstract}
Naomi : Kamu tidak sendirian
Naomi : Mungkin ini bukan urusanku

Naomi : Tapi kamu harus menghindari orang sepertinya, mengerti?
\end{abstract}

Pertama kali Naomi melihat Tomo bersama Rinko di toko swalayan dia langsung menghampiri Tomo. Naomi memanggil Rinko dengan julukan "orang aneh" dan juga meminta Tomo untuk menghindari Rinko. Mendengar hal tersebut Tomo marah dan menyemprotkan sabun cuci piring pada Naomi. Selain itu, setelah insiden tersebut terjadi Naomi juga melarang Kai untuk berhubungan dengan Tomo dan Rinko. Naomi kemudian mengatakan bahwa Rinko adalah orang yang tidak normal,

$$
\begin{aligned}
& \text { ナオミ：いっしよに行った見たでしよ。 } \\
& \text { ナオミ：普通じやないの。 } \\
& \text { カイ：「普通」つて何。 } \\
& \text { ナオミ：普通は普通、いじようでないことよ。 }
\end{aligned}
$$

Naomi : Kamu lihat orang yang bersamanya kan.

Naomi : Itu gak normal kan.

Kai : Normal itu, apa?

Naomi : Normal ya normal. Tidak aneh.

Selain Naomi, Hiromi atau kakak dari Makio juga memberikan cap pada Rinko. Meski tidak mengucapkan kata julukan secara langsung. Hiromi mengatakan tentang pandangan seksual Makio yang menurutnya salah. Hiromi tidak mengizinkan dan tidak rela jika Makio dan Rinko mengadopsi Tomo.

$$
\begin{array}{ll}
\text { マキオ } & \text { : 本当に母親になりたい言ってくれてるんだ。 } \\
\text { ヒロミ } & \text { :そんなに、無理決まってるんじゃない。だって。。。 } \\
\text { ヒロミ } & \text { :マキオ } \\
\text { ヒロミ } & \text { :あんたのせいしこいについて私何もよわない。 }
\end{array}
$$




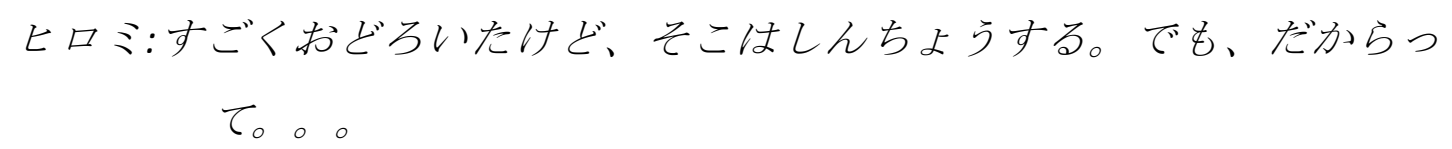

Makio : (Rinko) sangat ingin menjadi ibunya

Hiromi : Itu tidak mungkin, karena...

Hiromi : Makio

Hiromi : Aku tidak pernah mengatakan apapun soal pandangan seksualmu

Hiromi : Memang mengejutkan tapi aku sudah menduganya, maka dari itu...

\subsection{Analisis Dampak Heteronormativitas terhadap Aspek-Aspek Sosial}

Wellek dan Warren (1989) dalam bukunya tentang "Kitab Belajar Sastra" membuat klasifikasi mengenai sosiologi sastra. Dalam klasifikasi tersebut terdapat poin tentang sosiologi sastra yang memasalahkan karya sastra itu sendiri. Pada bagian ini berarti yang menjadi pokok penelaahan adalah apa yang tersirat dalam karya sastra dan apa yang menjadi tujuannya.

Dalam kaitannya dengan film Karera ga Honki de Amu Toki wa (Close-Knit) ini, Naoko Ogigami juga memiliki tujuan dalam karyanya. Menunjukkan bagaimana kehidupan transeksual sebagai representasi individu dengan seksualitas minoritas atau LGBT tentunya berkaitan dengan adanya masyarakat heteronormatif. Pengaruh masyarakat heteronormatif terhadap kehidupan sosial tokoh transeksual dalam film ini, digolongkan ke dalam beberapa aspek sosial berikut ini.

\section{Pendidikan}

Pendidikan menjadi aspek penting bagi setiap individu, pendidikan juga merupakan hak yang wajib diperoleh bagaimanapun kondisi seorang individu. Akan tetapi pada praktiknya banyak individu yang belum dapat memperoleh pendidikan layak sebagaimana mestinya.

Aspek pendidikan yang tercermin dalam film Karera ga Honki de Amu Toki wa (CloseKnit) ini adalah adanya sekolah Rinko di masa lalu. Sekolah rinko adalah sekolah umum atau sekolah biasa dan tidak memfasilitasi orang dengan seksualitas selain heteroseksual. Dengan kata lain meskipun Rinko tidak ingin berlatih Judo dengan anak laki-laki maka Rinko tidak punya 
pilihan lain. Dialog di bawah ini menunjukkan percakapan antara Fumiko dan guru Rinko. Dari percakapan ini dapat diketahui jika pihak sekolah tidak memberikan toleransi terhadap Rinko yang tidak mau mengikuti pelajaran olahraga. Meski Fumiko mencoba menjelaskan namun pihak sekolah angkat tangan dan membebankan semua kesalahan pada Rinko.

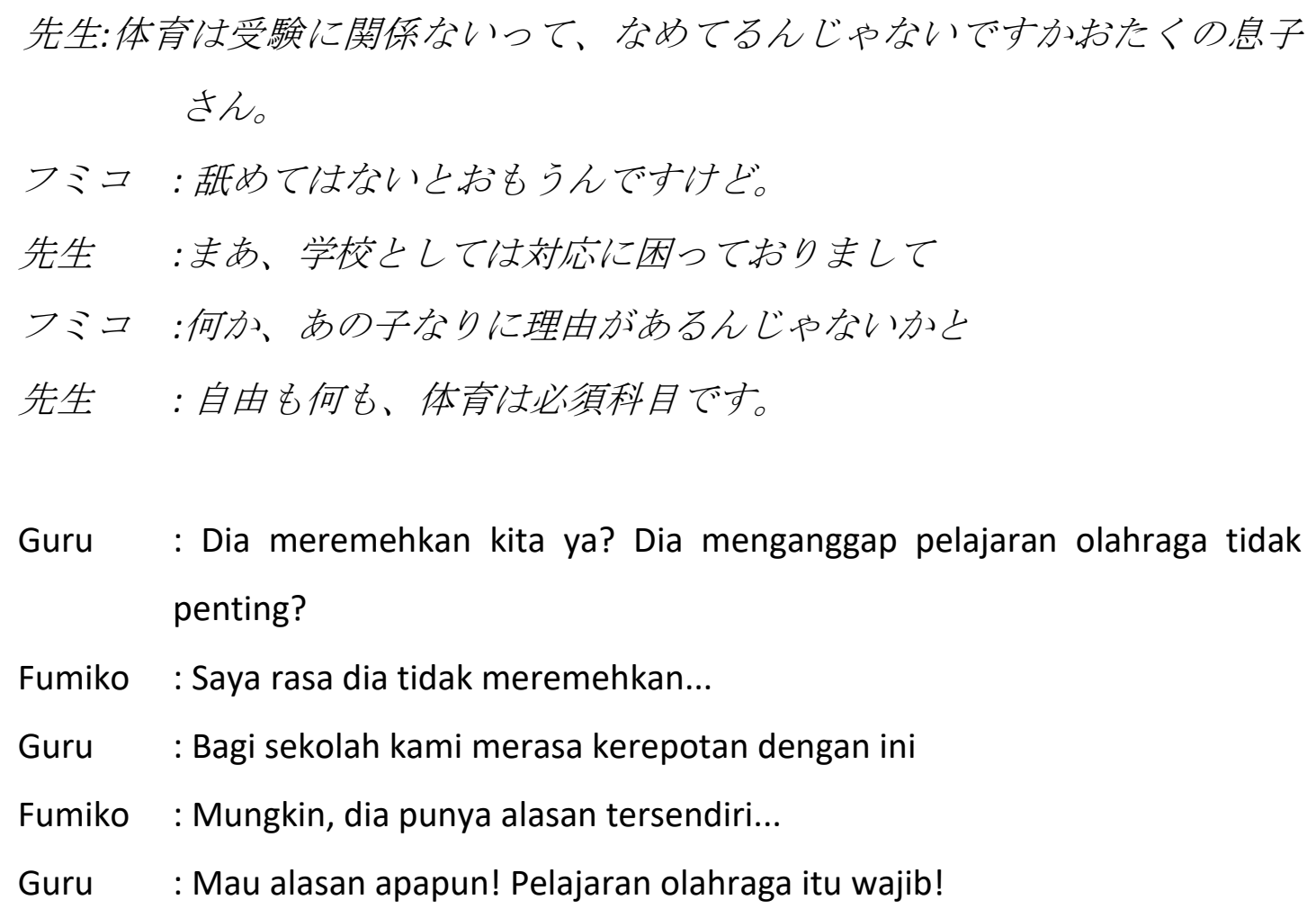

Sekolah yang tidak memberikan toleransi terhadap individu dengan gejala ketidakstabilan gender akan menciptakan lingkungan dengan suasana yang tidak nyaman bagi individu tersebut. Akibatnya mereka akan merasa terkucilkan dan tidak dihargai, dampak lebih lanjut akan berakhir dengan membolos atau keluar dari sekolah.

2. Ekonomi

Meski sebagai seorang transeksual Rinko kerap kali menerima perlakuan tidak baik dari masyarakat. Kehidupan sosial Rinko tidak sepenuhnya dapat dikatakan gagal. Dalam film Karera ga Honki de Amu Toki wa (Close-Knit) ini, Rinko mempunyai pekerjaan yang cukup bagus yaitu sebagai perawat di panti jompo. Di tempat bekerjanya Rinko tidak pernah mendapatkan perlakuan buruk baik dari pasien atau sesama pengurus panti jompo tersebut. 

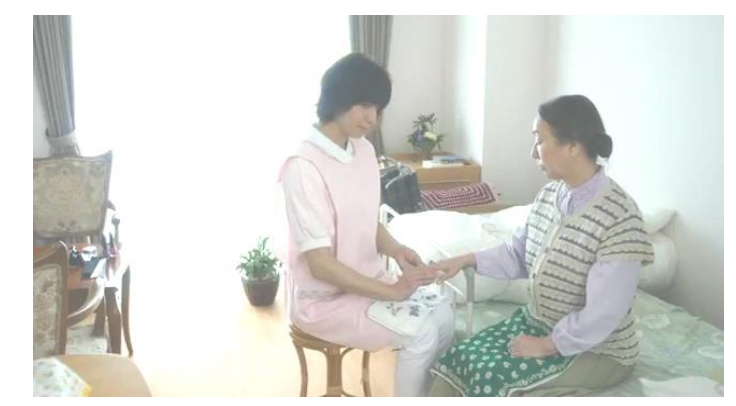

Gambar 2 (Close Knit 2017, Adegan 00:37:54)

Adegan di atas menjelaskan Rinko ketika sedang bekerja dan merawat ibu Makio yang juga merupakan salah satu pasien di panti jompo tempat dia bekerja. Tidak dijelaskan secara pasti apakah Rinko mengalami hambatan sebelum memperoleh pekerjaan ini. Meski demikian pekerjaan Rinko berada di lingkungan yang baik di mana tidak ada pengurus panti jompo yang memperlakukannya secara tidak baik. Selain itu pasien di panti jompo tersebut kebanyakan adalah orang tua yang sudah linglung sehingga tidak mempermasalahkan identitas Rinko.

Dengan demikian heteronormativitas masyarakat tidak terlalu berpengaruh secara langsung terhadap aspek ekonomi di kehidupan sosial tokoh Rinko. Meski demikian masih ada dampak yang diakibatkan. Dampak ini berkaitan dengan jenis pekerjaan yang dapat diperoleh. Dengan kata lain jika pekerjaan yang diperoleh cocok dan dapat menerima kondisinya sebagai seorang transeksual maka Rinko dapat bekerja di tempat tersebut. Rinko dapat memilih pekerjaan yang ingin dia lakukan, namun ada kemungkinan mendapat penolakan karena penampilan fisiknya.

\section{Agama}

Menurut Kamus Besar Bahasa Indonesia (2005: 12), agama adalah ajaran, sistem yang mengatur tata keimanan (kepercayaan) dan peribadatan kepada Tuhan Yang Mahakuasa serta tata kaidah yang berhubungan dengan pergaulan manusia dan manusia serta lingkungannya. Dalam film Karera ga Honki de Amu Toki wa (Close-Knit) tidak diketahui agama apa saja yang dianut oleh tokoh dalam film tersebut. Hanya tokoh Rinko yang menyinggung mengenai ajaran Budha, kuil dan gereja.

$$
\text { リンコ :百八ってのは、人間の煩悩の数 }
$$




\section{リンコ：除夜の鐘は大脢日の夜二百八回でしょう \\ リンコ : 数珠の玉の数も百八}

Rinko : Menurut ajaran Budha jumlah keinginan manusia ada 108

Rinko : Lonceng kuil berdentang 108 kali saat tahun baru

Rinko : Dan tasbih nyanyian gereja juga ada 108

Meski demikian tidak diketahui agama Rinko yang sebenarnya dan tidak ada adegan yang memperlihatkan kegiatan sedang beribadah atau berdoa. Akan tetapi tokoh Rinko sebenarnya percaya dengan adanya Tuhan. Hal ini dibuktikan dengan dialog berikit ini.

$$
\begin{aligned}
& \text { リンコ：何であたしはこんな苦しいおもしなくちゃいけないんだううって } \\
& \text { リンコ：あたし何か間違ったしたことかなって } \\
& \text { リンコ:間違ったのはあたしじやなくて神樣があたしのぞうけん閒違ったん } \\
& \text { だけど }
\end{aligned}
$$

Rinko : Kenapa aku harus menahan derita seperti ini?
Rinko : Apakah aku melakukan kesalahan?
Rinko : Tapi itu bukan kesalahanku, Tuhan yang salah menciptakan ragaku

Meski Rinko percaya dengan adanya Tuhan, dalam film Karera ga Honki de Amu Toki wa (Close-Knit) ini, Rinko menyalahkan Tuhan atas dirinya. Rinko menganggap Tuhan telah salah menciptakan dirinya.

Dapat disimpulkan bahwa pengaruh yang terjadi dalam aspek agama ini berkaitan dengan norma agama yang berlaku dalam masyarakat tersebut. Apabila agama yang mereka anut tidak membenarkan mengenai segala bentuk perilaku tidak normal maka mereka akan menganggap perbuatan tersebut adalah dosa dan individu yang melakukan hal tersebut adalah pendosa. 


\section{Sosial}

Pengaruh dalam aspek sosial dalam film ini, yang pertama berkaitan pula dengan aspek kesehatan. Rinko tidak mendapat perlakuan yang baik dalam hal pelayanan kesehatan. Terdapat adegan di mana Rinko secara tiba-tiba terluka dan harus di rawat di rumah sakit. Tidak dijelaskan secara pasti penyebab Rinko terluka. Akan tetapi Rinko harus dirawat di rumah sakit karena luka di bagian kepala dan tangan. Pihak rumah sakit kemudian menempatkan Rinko di bangsal laki-laki. Makio marah karena merasa ada diskriminasi dan pelanggaran HAM. Hal tersebut terjadi karena meskipun Rinko sudah operasi kelamin menjadi seorang perempuan, tetapi kartu asuransinya masih menunjukan data dirinya sebagai seorang laki-laki. Karena hal tersebut Rinko tidak bisa dipindahkan ke bangsal perempuan.

$$
\begin{aligned}
& \text { ナース：念のため検査入院です、たったいっぱく、我曼できませんか } \\
& \text { マキオ:できないから言ってるんです。彼女は女性です。見ればあかりじやな } \\
& \text { ルですか。 } \\
& \text { ナース：しょうでは男性ですからね。 } \\
& \text { マキオ：なんとくできません。すぐに女性でむちゅしください。 } \\
& \text { ナース：あきがないんです。 } \\
& \text { マキオ :だからって、 } \\
& \text { ナース：一泊四十万いけますけど、そちらによ゙うされますか。 } \\
& \text { マキオ：あなたやってること陣化身間、差別わかってるんですか } \\
& \text { ナース :大きな声出さないでください。 } \\
& \text { Perawat :Dia hanya perlu ditest. Bisakah anda menahannya semalam saja? } \\
& \text { Makio :Sudah kubilang tidak bisa. Dia itu perempuan. Bukannya sudah jelas? } \\
& \text { Perawat :Tapi di kartu ansuransinya tertulis laki-laki sih. } \\
& \text { Makio :Saya tidak bisa menerima ini. Tempatkan dia di bangsal khusus } \\
& \text { perempuan. } \\
& \text { Perawat :Kami kehabisan tempat tidur. } \\
& \text { Makio :Lalu bagaimana? }
\end{aligned}
$$


Perawat :Di sini terdapat ruang pribadi dengan biaya 400 ribu yen semalam. Apa perlu kita pindah ke sana?

Makio :Hal yang kamu lakukan ini melanggar HAM. Ini diskriminasi kau tahu!

Perawat :Tolong pelankan suara anda

Dialog di atas menunjukkan bahwa Rinko masih kesulitan untuk mendapatkan perlakuan sebagaimana mestinya sebelum dia merubah seluruh identitasnya. Selain itu Rinko dan Makio juga sempat diperiksa oleh lembaga perlindungan anak. Mereka dicurigai memberikan lingkungan tempat tinggal yang tidak baik bagi Tomo.

Hal tersebut membuktikan bahwa identitas Rinko sebagai transeksual masih belum mendapat kepercayaan dari lingkungan sosialnya. Meski Rinko merawat Tomo dengan baik dia masih dicurigai tidak dapat menciptakan lingkungan yang baik bagi Tomo. Rinko seringkali dipersulit dalam banyak hal dan tidak dapat dengan mudah melakukan suatu hal sesuai dengan kehendaknya.

5. Budaya

Dalam film Karera ga Honki de Amu Toki wa (Close-Knit) ini terdapat sebuah adegan pernikahan. Pernikahan tersebut adalah pernikahan dari teman kerja Rinko bernama Yuka. Rinko sangat mendukung temannya ini untuk menikah.

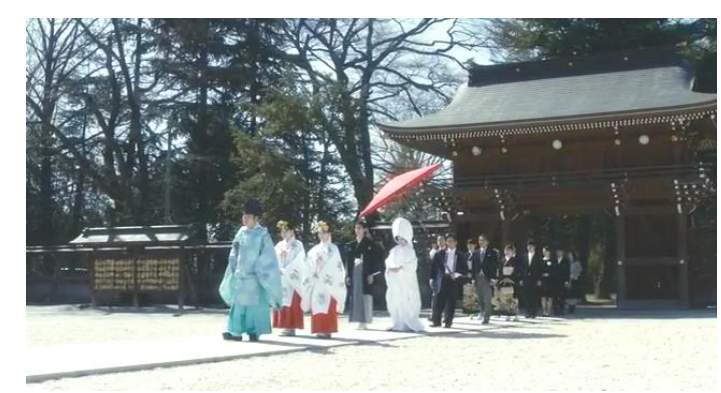

Gambar 3 (Close Knit 2017, Adegan 01:20:11)

Makio dan Rinko juga merencanakan untuk menikah karena berniat mengadopsi Tomo. Meski homoseksualitas di Jepang sudah dilegalkan tapi pernikahan sesama jenis masih tabu dan belum diakui. Menurut data Equaldex yang merupakan sebuah portal penyedia data mengenai 
LGBT wilayah Jepang, terhitung hingga 9 September 2018 beberapa daerah di Jepang mengakui adanya civil unions. Civil unions adalah istilah untuk serikat yang diakui secara hukum untuk pasangan sesama jenis, dengan hak-hak yang serupa dengan pernikahan. Sementara itu baik civil unions atau pernikahan sesama jenis masih belum diakui secara nasional. Dengan demikian Rinko dan Makio belum dapat menikah jika Rinko belum mengganti jenis kelaminnya menjadi perempuan secara legal.

$$
\begin{aligned}
& \text { リンコ :わたし戸籍女に変えて。 マキオと結婚したら。 } \\
& \text { リンコ :トモのmama になれるのかな }
\end{aligned}
$$

Rinko :Aku akan merubah data di daftar keluarga menjadi perempuan.menikah dengan makio

Rinko : : Apakah aku bisa menjadi mama nya Tomo?

Selain sulitnya regulasi untuk melakukan pernikahan bagi seorang transeksual, mereka masih harus menghadapi tantangan lainnya. Banyak anggapan-anggapan dari masyarakat yang mungkin tidak setuju dengan adanya pernikahan tersebut. Seperti halnya dalam pembahasan sebelumnya tokoh Hiromi memandang sebelah mata mengenai orientasi seksual Makio karena memiliki kekasih seorang transeksual. Bahkan Fumiko yang sangat mendukung Rinko sempat merasa pesimis anaknya tidak akan dapat menikah.

$$
\begin{aligned}
& \text { フミコ :だって、そうでしょー どんなに頑張っても結構はむりかなって } \\
& \text { と思ったけよ゙、牧夫君みたいな理解男性がみつかて、 } \\
& \text { フミコ：それだけで、じゅぶんすごくと思ったのに、ましてそのフミコ } \\
& \text { :お父さんいなくなってて、お母さんはその。。 } \\
& \text { フミコ :んーなんて言うかー } \\
& \text { Fumiko : Kupikir seberapa usahanya pun, menikah sepertinya tidak mungkin. Tapi } \\
& \text { kau bertemu pria serius seperti Makio-kun. } \\
& \text { Fumiko : Bukankah hal itu luar biasa. Ayahnya sudah meninggal, lalu ibunya.. } \\
& \text { Fumiko : Bagaimana aku mengatakannya? } \\
& \text { Rinko :lbu! }
\end{aligned}
$$


Kekhawatiran yang sempat dialami Fumiko ini menandai bahwa kebanyakan masyarakat Jepang akan sulit menerima seorang transeksual untuk menjadi menantu keluarga mereka. Dalam film ini Rinko bertemu dengan Makio meski mereka dapat menikah setelah Rinko mengganti data kependudukannya, mereka gagal mengadopsi Tomo sebagai anak mereka. Hal tersebut dikarenakan Hiromi tidak menginginkan anaknya dirawat oleh seorang transeksual. Hiromi menganggap Rinko tidak mampu menjadi ibu bagi Tomo.

Dalam film Karera ga Honki de Amu Toki wa (Close-Knit) ini, tokoh Rinko masih kesulitan untuk membuktikan identitasnya. Dia masih harus berjuang lebih dan menghadapi berbagai masalah jika ingin menikah dan mengadopsi anak. Jika individu transeksual sulit mendapatkan pasangan karena identitas mereka, maka dampak yang akan terjadi adalah individu tersebut tidak akan menikah.

Dari beberapa aspek-aspek sosiologis dalam kehidupan transeksual di atas dapat disimpulkan bahwa masyarakat heteronormatif sangat berpengaruh terhadap kehidupan sosial mereka. Aspek yang sangat berdampak terhadap transeksual adalah aspek pendidikan. Masyarakat heteronormatif sangat berpengaruh terhadap aspek pendidikan tokoh transeksual Karena berinteraksi secara langsung dan dalam waktu yang konstan maka dampak yang terjadi pada individu transeksual pun dapat dilihat secara langsung. Misalnya tokoh Rinko yang kemudian selalu membolos di setiap pelajaran olahraga. Dengan kata lain tokoh transeksual telah mendapatkan beberapa hak mereka seperti hak untuk mendapat pendidikan dan bekerja. Akan tetapi di sisi lain mereka masih memperjuangkan hak-hak mereka yang agar diperlakukan sama oleh masyarakat. Meski Jepang adalah negara yang cukup dianggap toleran, mereka belum sepenuhnya dapat menerima individu transeksual. Meski Transgender dalam film ini telah memperoleh beberapa hak mereka, akan tetapi masyarakat heteronormatif tidak menciptakan lingkungan yang aman da aman dan nyaman untuk mereka.

\section{Simpulan}

Tindakan pemberian cap atau labeling yang tidak baik yang diterima oleh tokoh transeksual Rinko dalam film ini menggambarkan bahwa masih ada sebagian masyarakat Jepang yang belum menerima eksistensi kaum transeksual. Tokoh Rinko berulang kali 
mendapat julukan orang aneh atau tidak normal. Hal tersebut menunjukkan adanya masyarakat heteronormatif yang sangat berpengaruh dalam kehidupan sosial individu transeksual. Dari lima aspek sosiologi yang dianalisis mengenai film ini dapat disimpulkan bahwa meskipun Jepang adalah negara yang dianggap toleran, mereka belum mampu sepenuhnya menerima kaum transgender dalam lingkungan sosial mereka. Khususnya pada aspek-aspek seperti aspek pendidikan, sosial dan budaya, tokoh Rinko masih sangat mengalami kesulitan dalam memperoleh perakuan adil dari setiap lapisan masyarakat. Tetapi meskipun tokoh Rinko menerima perlakuan kurang adil dari sebagian individu masyarakat di sekitarnya, Rinko menjalani kehidupan layaknya seperti orang normal, dia mempunyai seorang kekasih yang sangat mencintainya, dia juga mempunyai seorang ibu yang mau menerima dia apa adanya dan selalu berusaha melindungi Rinko dari gangguan masyarakat sekitar. Dia juga bisa bekerja sebagai perawat di panti jompo. Hal ini menunjukkan adanya masyarakat Jepang yang bisa menerima individu transeksual. Dengan demikian, penulis menyarankan agar pembaca tidak melakukan tindakan labeling atau memberikan cap secara ekstrem terhadap individu yang dianggap berbeda. Setelah membaca penelitian ini, pembaca diharapkan dapat memahami lebih lanjut mengenai pengaruh masyarakat heteronormatif terhadap transeksual dan gay atau LGBT lainnya. Dengan demikian pembaca dapat menentukan sikap yang tepat berkaitan dengan permasalahan tersebut.

\section{Daftar Pustaka}

Pratista, Himawan. (2008). Memahami Film. Yogyakarta: Homerian Pustaka. Noor, Redyanto. (2005). Pengantar Pengkajian Sastra. Jasindo. Narwoko, J.D dan Suyanto, B. (2007). Sosiologi: Teks Pengantar Dan Terapan. Jakarta: Kencana.

Green J .(2004). Becoming a Visible Man. 1st edn. Nashville. TN: Vanderbilt University Press. Bornstein, K. (1994). Gender Outlaw: On men, women, and the rest of us. New York: Vintage Books.

Hird, MJ .(2002). For a Sociology of Transsexualism. Sociology 36: 577-595.

Nagoshi, J. L., Adams, K. A., Terrell, H. K., Hill, E. D., Brzuzy, S., \& Nagoshi, C. T. (2008). Gender differences in correlates of homophobia and transphobia. Sex Roles, 59, 521-531.

Wellek, R dan Warren, A. (1993). Teori Kesusastraan. Jakarta: PT GramediaGreen J .2004. Wellek, Renne dan Austin Warren, Melani Bidianto. (1993). Teori Kesustraan. Gramedia. 